\title{
Erweitern Sie Ihr Profil
}

Die FMH baut den FMH-Ärztelndex aus. Das einzige offizielle, komplette und stets aktuelle Verzeichnis der Ärztinnen und Ärzte in der Schweiz verfügt seit dem 31. Januar 2008 über eine zweite Suchmaske. Diese richtet sich an die gesamte Bevölkerung. So profitieren vom FMH-Ärztelndex nicht nur Health Professionals, sondern auch Patientinnen und Patienten.

Generalsekretariat der FMH, Abteilung Dienstleistungen/ Mitgliedschaft
Neu präsentiert sich der FMH-ÄrzteIndex in einem attraktiven, benutzerfreundlichen Design mit nützlichen Sonderfunktionen wie der geographischen Suche oder der Suchmaske für das breite Publikum. Diese neue Maske ersetzt drei alte durch zwei neue Suchkategorien: Facharzttitel, Schwerpunkte und Fähigkeitsausweise werden zu Fachgebiet und Spezialisierung. Zudem sind die medizinischen Fachgebiete in der allgemeinsprachlichen Berufsbezeichnung so aufgeführt, wie sie im Telefonbuch zu finden sind.

Profitieren auch Sie vom erweiterten FMHÄrzteIndex, vervollständigen Sie Ihr Profil über www.myfmh.ch: Sie können Ihre medizinischen Tätigkeitsgebiete angeben, Ihren Werdegang, Mitgliedschaften in Fachorganisationen und natürlich Ihren Webauftritt. Von besonderem Wert dürfte für Ihre Patientinnen und Patienten die Angabe von Sprachkenntnissen sein.

Fragen Sie uns, wenn Sie mehr über den ausgebauten FMH-ÄrzteIndex wissen wollen. Bei Schwierigkeiten mit dem Login oder der Registrierung in $m y \mathrm{FMH}$ helfen wir gerne weiter telefonisch über unsere Helpline (031 359 12 59) oder via E-Mail (info-dig@fmh.ch).

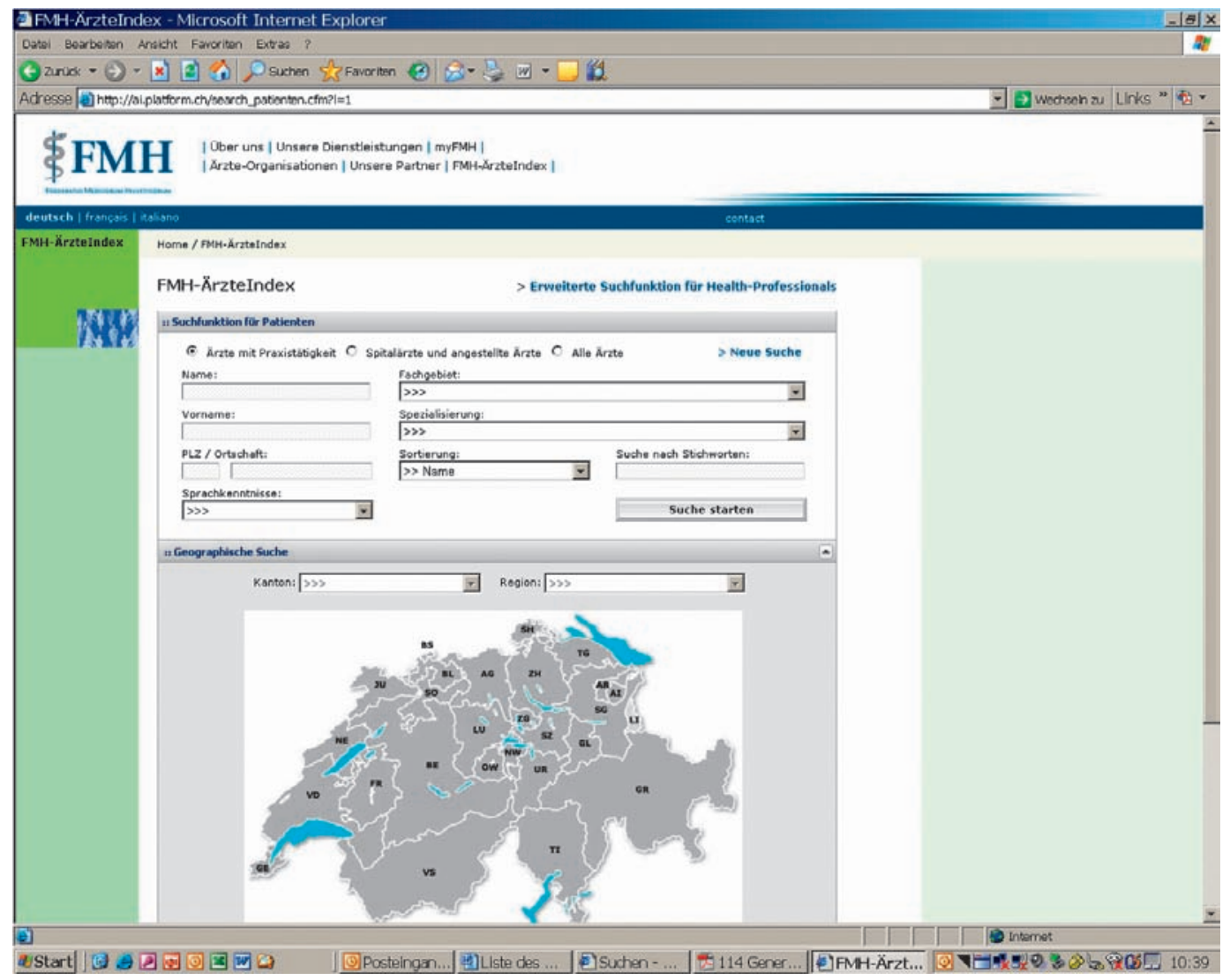

